\title{
Reliability of Power Distribution Networks With Renewable Energy Sources
}

\author{
K. Prakash, F. R. Islam, K. A. Mamun, A. Lallu and M. Cirrincione \\ School of Engineering \& Physics (SEP), The University of the South Pacific, Suva, Fiji \\ E-mail: s11084683@student.usp.ac.fj
}

\begin{abstract}
To improve economical, technological and social growth of a community, stable and reliable power supply is essential. The electric power companies around the world are working to meet the customer satisfaction with major concern of reducing power failure rates in distribution networks. Appropriate information on systems performance is required to measure and improve the reliability of the system. In this paper, IEEE 13 bus radial distribution network has been converted in to ring and mesh networks to identify their reliability based on reliability indices and factors. Finally, renewable energy sources have been integrated into the ring and mesh networks to determine the networks performance with comparison to the fossil fuel based distributed generation.
\end{abstract}

Index Terms - reliability, distribution networks, radial, ring and mesh network.

\section{INTRODUCTION}

Distribution system consists of distribution substation, primary distribution feeder, distribution transformer and service mains. The key role of distribution networks is to supply power to individual customer premises over the distribution lines. Reliability of distribution networks is the ability to supply continuous power to the customers [1], [2]. Numerical description of reliability can be identified using the standard indices and reliability factors (i.e. average failure rate, annual unavailability and average outage time) [3], hence; the power supply company's major focus is to improve the maintenance program for the distribution network components to reduce the failure rate [4]-[7].

A single fault in any component or part of the distribution network will lead to unreliable and dis-continuous power supply. For instance, any failure in the distribution line will affect a number of customers connected to the corresponding line. Based on the type of fault the restoration time varies: with a minor fault (which can be isolated), the restoration time will be less however; restoration time can be increased for a major fault in the system.

Reliability of a system mainly depends upon the load and operation [8], while different weather conditions also has a huge impact on the system performance [9], while reduction in the power outage time, size of fault, affected area and average fault frequency can also affect the reliability [3]. To improve the reliability, power utility companies around the globe are working to improve data gathering schemes so that the maintenance program of distribution networks can be managed [10].

Components with low failure rates can be used in power distribution networks to reduce the average failure. For example, in the cyclone prone regions, the overhead transmission lines can be replaced with the underground cables to minimize the faults occurrences during cyclone. Average failure rate can be minimized by implementing a well scheduled maintenance program for the distribution network and its components. Power outage time can also be reduced if restoration equipment such as temporary generation units and cables are available as back up [10].

In this paper, IEEE 13 bus radial distribution network has been converted to design ring network and to mesh network for the reliability test of distribution systems. The reliability factors; average failure rate, annual unavailability and average outage time together with the reliability indices; System Average Interruption Frequency Index (SAIFI), System Average Interruption Duration Index (SAIDI), Customer Average Interruption Duration Index (CAIDI), Average Service Availability Index (ASAI) and Average Service Unavailability Index (ASUI) have been used to measure the reliability of each network with and without renewable energy sources. The paper then concludes with a summary of comparison between the reliability and performance of the two networks with and without renewable energy sources.

\section{RELIABILITY INDICES}

To predict or asses the reliability of power distribution networks, it is important to use the three primary reliability factors: average failure rate, average outage duration and annual unavailability which are also known as the load point indices. For the complete understanding of a system behavior along with these indices a set of customer and load oriented indices: SAIFI, SAIDI, CAIDI, ASAI and ASUI [11-14] are used to represent the overall networks performance. Reliability factors and indices used in this research have been described in the next section of this paper.

\section{1) Average Failure Rate (f/yr)}

Average Failure Rate is represented using a Greek symbol lamda $(\lambda)$ and is defined by the rate at which an electrical component or network fails; expressed in failures per unit time. The fundamental equation of Average Failure Rate is shown by Eq. 1 .

$$
\lambda_{t}=\sum_{i} \lambda_{i}
$$

Where, $\lambda_{t}$ is the average failure rate and $\sum_{i} \lambda_{i}$ is the sum of failures for $\mathrm{i}=1,2,3 \ldots \mathrm{N}$. 


\section{2) Annual Unavailability (hr/yr)}

Annual unavailability, also known as annual outage time; is the total time of power failure in a year which is measured in hours per year. The fundamental equation of annual unavailability is given by Eq. 2 .

$$
U_{t}=\sum_{i} \lambda_{i} r_{i}
$$

Where, $U_{t}$ is the annual outage time and $r$ is the average outage time for $\mathrm{i}=1,2,3 \ldots \mathrm{N}$.

\section{3) Average Outage Duration (hr)}

Average outage duration is the ratio of annual unavailability of power over the average failure rate. The fundamental equation of average outage time is given by Eq. 3 .

$$
r_{t}=\frac{\sum_{i} \lambda_{i} r_{i}}{\sum_{i} \lambda_{i}}
$$

\section{4) System Average Interruption Frequency Index, SAIFI} (f/customer.yr)

SAIFI indicates the frequency or rate at which the customer faces power interruptions in their respective areas in a year. SAIFI is calculated by the ratio of total number of customer interruptions over the total number of customers served. The fundamental equation of SAIFI is given by Eq. 4 .

$$
\text { SAIFI }=\frac{\text { Total number of customer interruptions }}{\text { Total number of customers served }}=\frac{\sum_{i} \lambda_{i} N_{i}}{\sum_{i} N_{i}}
$$

Where, $N_{i}$ is the number of customer at the load point $\mathrm{i}=1$, $2,3 \ldots \mathrm{N}$.

\section{5) System Average Interruption Duration Index, SAIDI (hr./customer.yr)}

SAIDI indicates the total duration of customer interruptions over a period of time. It is found by the ratio of total customer interruption duration over the total number of customers as shown by Eq. 5 .

$$
S A I D I=\frac{\text { Sumofcustomerinterruptionduration }}{\text { Totalnumberofcustomersserved }}=\frac{\sum_{i} U_{i} N_{i}}{\sum_{i} N_{i}}
$$

6) Customer Average Interruption Duration Index, CAIDI (hr. /customer interruption)

CAIDI indicates the average time to restore a fault. It can be determine by the ratio of sum of customer interruption durations over the total number of customer interruptions as shown by Eq. 6 .

$C A I D I=\frac{\text { Sum of customer interruption duration }}{\text { Total number of customers interruptions }}=\frac{\sum_{i} U_{i} N_{i}}{\sum_{i} N_{i} \lambda_{i}}$

\section{7) Average Service Availability Index, $A S A I(P u)$}

ASAI, also known as service reliability index is define as the ratio of total customer hours of available service to the total customer hours demanded. ASAI is usually calculated on a monthly or yearly basis. The fundamental equation of ASAI is given by Eq. 7 .

$$
\begin{gathered}
A S A I=\frac{\text { Customer hours of available service }}{\text { Customer hours demanded }} \\
\text { ASAI }=\frac{\sum_{i} N_{i} \times 8760-\sum_{i} N_{i} U_{i}}{\sum_{i} N_{i} \times 8760}
\end{gathered}
$$

Where, 8760 is the number of hours in a calendar year.

8) Average Service Unavailability Index, ASUI (Pu)

ASUI is defined as the ratio of time that customers were provided with the service over the time the customers had demanded for in a given time period as shown by Eq. 8 .

$$
A S U I=1-A S A I
$$

\section{TEST SYSTEMS}

In this work, reliability test has been done for modified IEEE 13 bus distribution networks using the ETAP (Electrical Transient Analyzer Program) software. Radial distribution network has been converted in to ring and mesh networks and reliability assessment has been carried out using the aforementioned reliability factors and indices. All the single phase parameters of IEEE 13 bus radial network data [15], [16] has been converted to three phase and shown in Table I to Table VI to have a fair comparison between the networks [17].

\section{1) Ring Network}

For IEEE 13 bus radial network, the transmission line connecting Bus 632 and 671 has been removed and two additional transmission lines have been connected; one between Bus 646 and 685 and the other one connected between Bus 634 and 675 to form a loop. Both the transmission lines are $1000 \mathrm{ft}$ long and follows 601 line configuration as shown in Table I. The rating of Bus 634 is $0.48 \mathrm{kV}$ and the rest of the Buses are rated $4.16 \mathrm{kV}$. Therefore, to synchronize the voltage ratings of every bus, a transformer is used between Bus 634 and 675 to step up the bus voltage from $0.48 \mathrm{kV}$ to $4.16 \mathrm{kV}$. At bus 684 and 692 , two $0.5 \mathrm{MW}$ generators have been added since the ring network allows connection of multiple generating sources. Fig. 1 shows the ring network that has been modeled using ETAP software.

Table I Overhead Transmission Line Configurations for Modified Network

\begin{tabular}{|c|l|l|l|l|}
\hline \multirow{2}{*}{ Configuration } & \multirow{2}{*}{ Phasing } & Phase & Neutral & Spacing \\
\cline { 3 - 5 } & & ACSR & ACSR & ID \\
\hline 601 & B A C N & 556, & $4 / 06 / 1$ & 500 \\
& & 500, & & \\
& & $26 / 7$ & & \\
\hline 602 & C A B N & $4 / 06 / 1$ & $4 / 06 / 1$ & 500 \\
\hline
\end{tabular}

Table II Underground Cable Configurations for Modified Network

\begin{tabular}{|l|l|l|l|l|}
\hline \multirow{2}{*}{ Configuration } & \multirow{2}{*}{ Phasing } & Cable & Neutral & Spacing \\
\cline { 5 - 5 } & & & ID \\
\hline 606 & A B C & $\begin{array}{l}250, \\
\text { N }\end{array}$ & None & 515 \\
& & AA, CN & & \\
\hline
\end{tabular}


Table III Line Segment Data for Modified Network

\begin{tabular}{|l|l|l|l|l|}
\hline Bus A & Bus B & $\begin{array}{l}\text { Overhead or } \\
\text { Underground }\end{array}$ & $\begin{array}{l}\text { Length } \\
\text { (ft.) }\end{array}$ & Configuration \\
\hline 632 & 645 & Overhead & 500 & 602 \\
\hline 632 & 633 & Overhead & 500 & 602 \\
\hline 633 & 634 & Transformer & 0 & XFM-1 \\
\hline 645 & 646 & Overhead & 300 & 602 \\
\hline 684 & 652 & Underground & 800 & 606 \\
\hline 632 & 671 & Overhead & 2000 & 601 \\
\hline 671 & 684 & Overhead & 300 & 602 \\
\hline 671 & 680 & Overhead & 1000 & 601 \\
\hline 671 & 692 & Switch & 0 & Switch \\
\hline 684 & 611 & Overhead & 300 & 602 \\
\hline 692 & 675 & Underground & 500 & 606 \\
\hline
\end{tabular}

Table IV Load data for Modified Network

\begin{tabular}{|l|l|l|l|l|l|l|l|l|}
\hline \multirow{2}{*}{ Bus } & \multirow{2}{*}{ Label } & Load & Ph-1 & Ph-1 & Ph-2 & Ph-2 & Ph-3 & Ph-3 \\
\cline { 3 - 9 } & & Model & $\mathrm{kW}$ & $\mathrm{kVAr}$ & $\mathrm{kW}$ & $\mathrm{kVAr}$ & $\mathrm{kW}$ & $\mathrm{kVAr}$ \\
\hline 645 & MTR & Y-PQ & 0 & 0 & 170 & 125 & 0 & 0 \\
\hline 611 & Lump & Y-I & 0 & 0 & 0 & 0 & 170 & 80 \\
\hline 652 & Load & Y-Z & 128 & 86 & 0 & 0 & 0 & 0 \\
\hline 671 & Lump & D-PQ & 385 & 220 & 385 & 220 & 385 & 220 \\
\hline 692 & Lump & D-I & 0 & 0 & 0 & 0 & 170 & 151 \\
\hline 646 & Load & D-Z & 0 & 0 & 230 & 132 & 0 & 0 \\
\hline 675 & Lump & Y-PQ & 485 & 190 & 68 & 60 & 290 & 212 \\
\hline 634 & Lump & Y-PQ & 160 & 110 & 120 & 90 & 120 & 90 \\
\hline
\end{tabular}

Table V Capacitor Data for Modified Network

\begin{tabular}{|l|l|l|l|}
\hline Node & Ph-A & Ph-B & Ph-C \\
\hline & kVAr & kVAr & kVAr \\
\hline 675 & 200 & 200 & 200 \\
\hline 611 & 0 & 0 & 100 \\
\hline
\end{tabular}

Table VI Transformer Data for Modified Network

\begin{tabular}{|l|l|l|l|l|l|}
\hline & kVA & kV-high & kV-low & R - \% & X - \% \\
\hline Substation: & 5,000 & 115 - D & 4.16 Gr. Y & 1 & 8 \\
\hline XFM - 1 & 500 & 4.16 - Gr.W & 0.48 - Gr.W & 1.1 & 2 \\
\hline
\end{tabular}

\section{2) Mesh Network}

Ring network used in this research has been further modified to form a mesh network in this section. Additions of two redundant transmission lines have set to work as backup transmission route in case of any fault arising at the network. A transmission line has been added between Bus 645 and 671 and the other has been added between Bus 633 and 671. Each line is considered to be $1000 \mathrm{ft}$ long with line configuration of 601. Fig. 2 shows the mesh network that has been modeled and simulated in ETAP.

\section{Simulation RESUlts AND Discussion}

Reliability of modified ring and mesh networks have been conducted using the aforementioned reliability indices and summarized in tabular format for the better understanding.
TABLE VII shows the reliability data of the two networks when distributed diesel generators (DDG) are connected at bus 684 and 692.

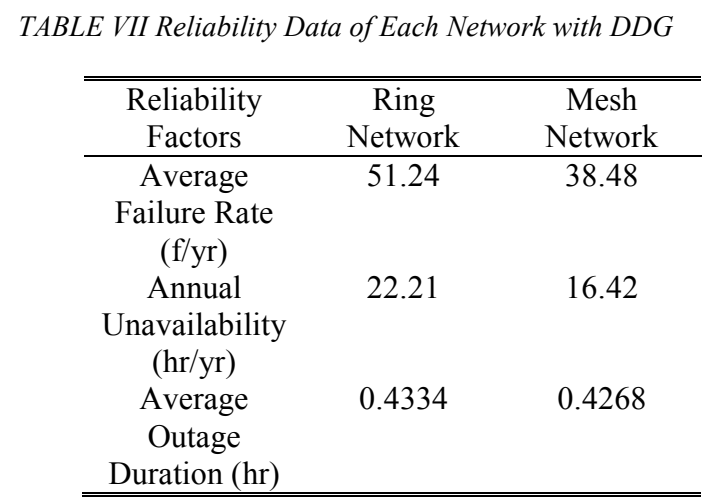

Based on the reliability data, it has been observed that the mesh network has average failure rate of 38.48 (f/yr) whereas the ring has $51.24(\mathrm{f} / \mathrm{yr})$. The annual unavailability of mesh network is $16.42(\mathrm{hr} / \mathrm{yr})$ which indicates that the total power outage in a year for this network is 16.42 hours whereas the annual unavailability for ring network is 22.21 hours. The average outage duration of mesh network is 0.4268 hours and ring 0.4334 hours. Reliability analysis based on the load point indices show that reliability factors are better for mesh network with less failures and less outages when compared to the ring network.

Apart from the reliability factors, reliability indices SAIFI, SAIDI, CAIDI, ASAI, and ASUI have also been used to determine the complete representation of each network. TABLE VIII shows simulation results of two networks based on these indices.

\begin{tabular}{ccc} 
TABLE VIII Reliability Indices Analysis with DDG \\
\hline \hline Reliability Indices & $\begin{array}{c}\text { Ring } \\
\text { Network }\end{array}$ & $\begin{array}{c}\text { Mesh } \\
\text { Network }\end{array}$ \\
\hline $\begin{array}{c}\text { SAIFI } \\
\text { (f/customer.yr) }\end{array}$ & 0.4334 & 0.4268 \\
$\begin{array}{c}\text { SAIDI } \\
\text { (hr/customer.yr) }\end{array}$ & 22.2115 & 16.4226 \\
$\begin{array}{c}\text { CAIDI } \\
\text { (hr/customer } \\
\text { interruption) }\end{array}$ & 51.245 & 38.476 \\
ASAI (pu) & 0.9975 & 0.9981 \\
ASUI (pu) & 0.00254 & 0.00187 \\
\hline \hline
\end{tabular}

It has been observed that the mesh network has lower value of SAIFI, SAIDI, CAIDI, ASAI and ASUI when compared with the ring which indicates that the reliability of the mesh network is better than the ring network since it has less number of failures and outages in a year. 


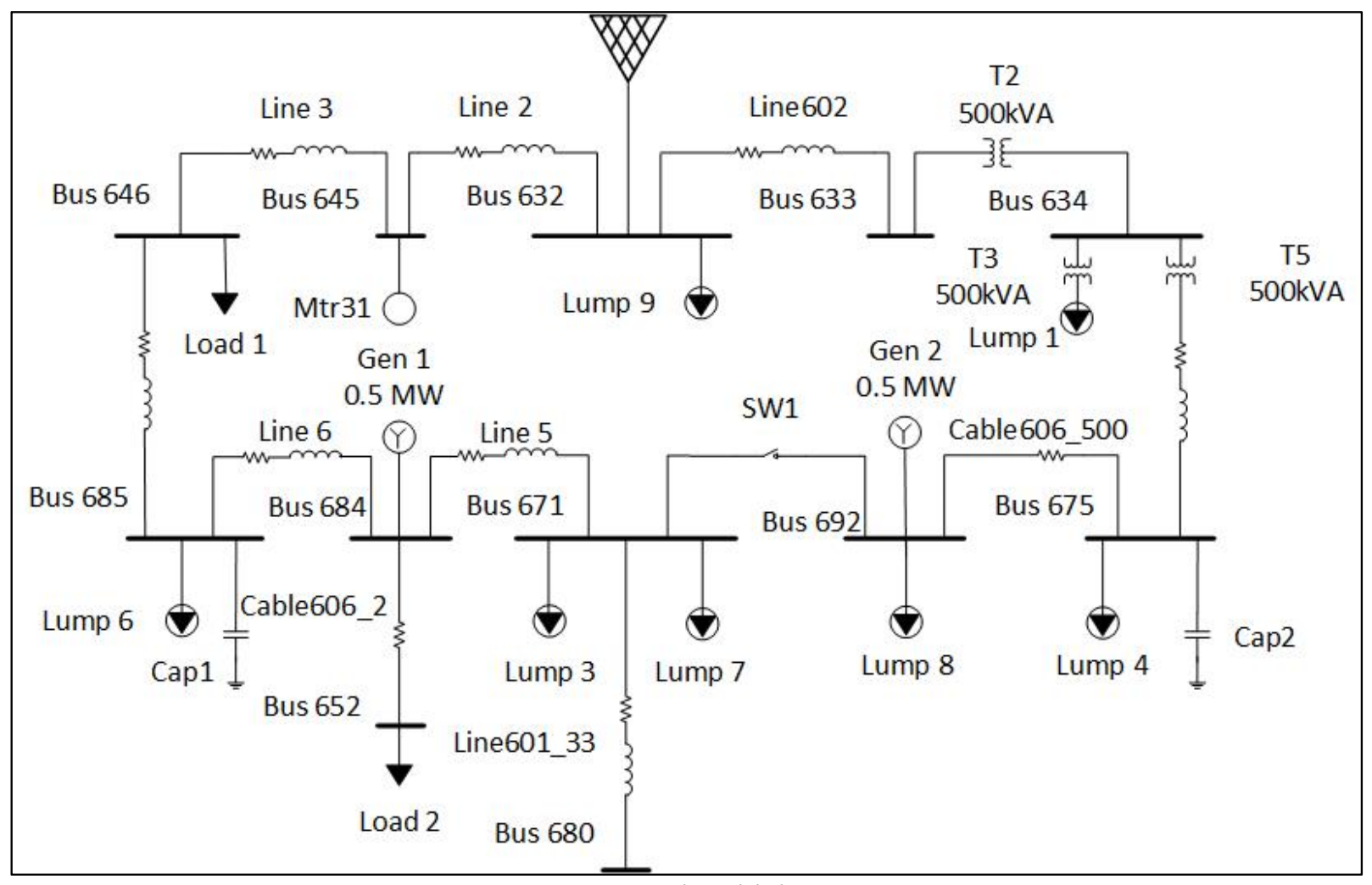

Fig. 1 Ring Network Modeled in ETAP.

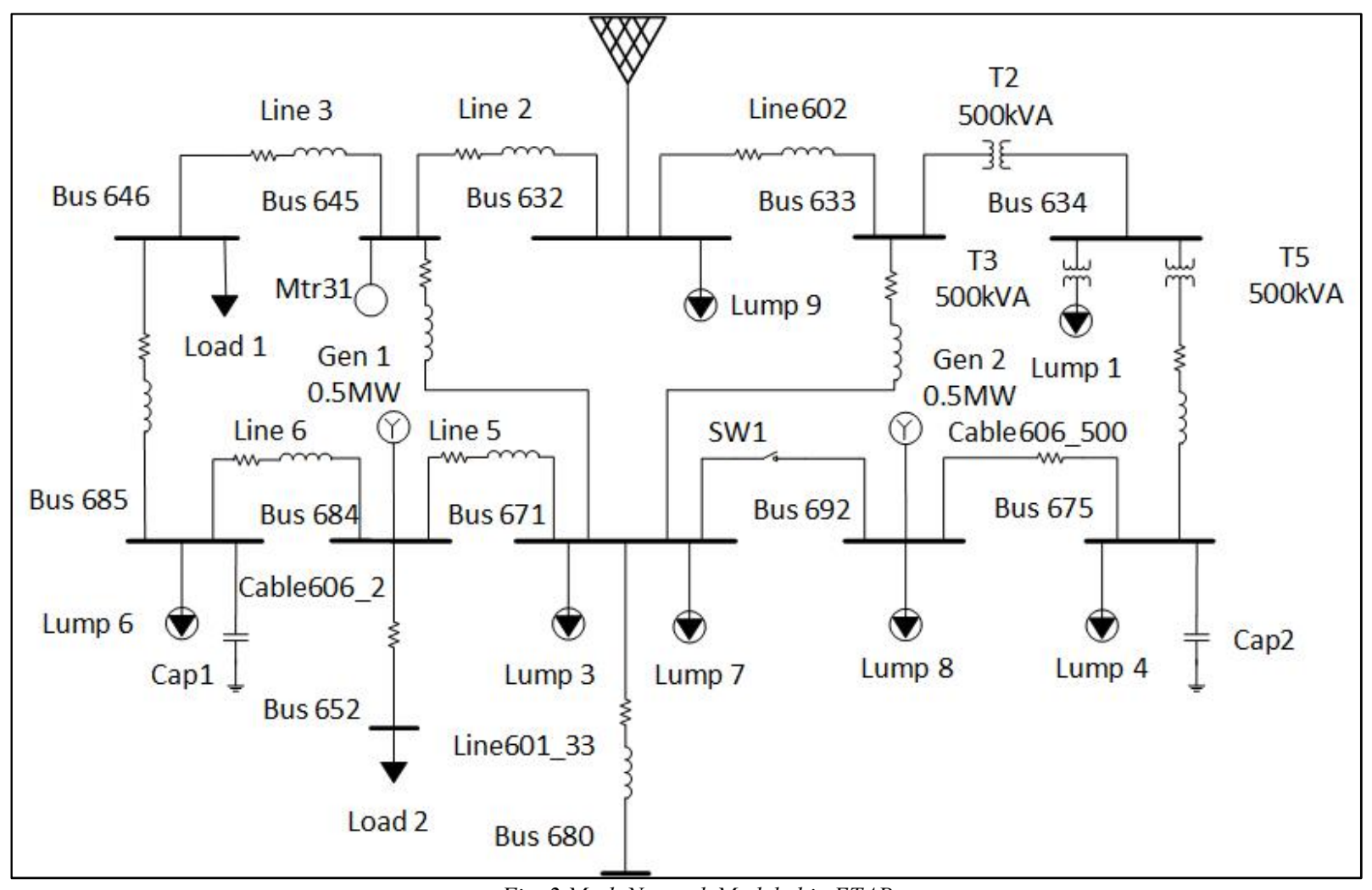

Fig. 2 Mesh Network Modeled in ETAP 


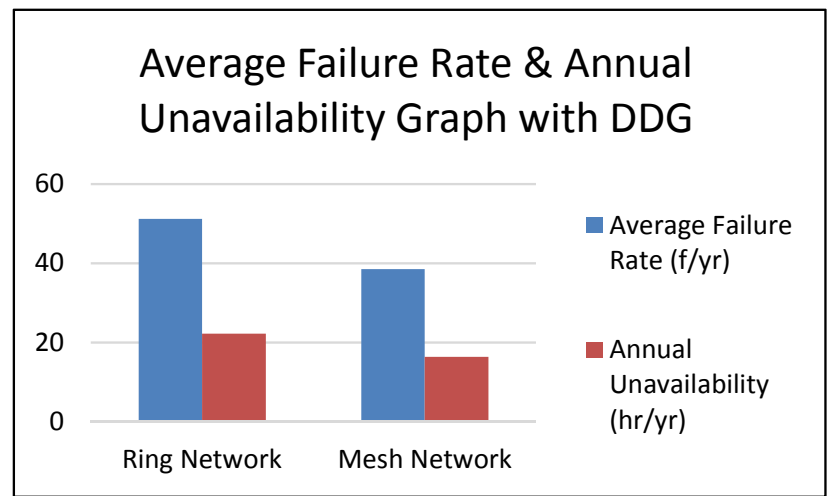

Fig. 3 Average Failure Rate \& Annual Unavailability Graph with $D D G$

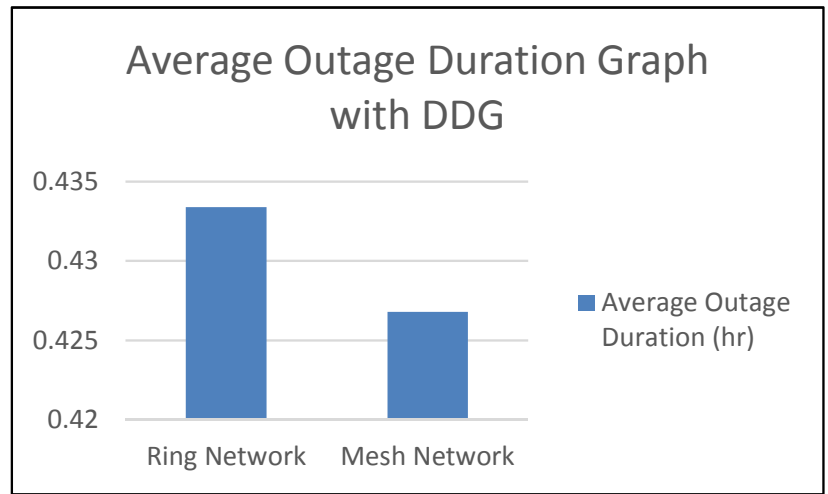

Fig. 4 Average Outage Duration Graph with DDG

Fig. 3 and Fig. 4 shows the results of reliability factors where mesh network has less failures and outages when compared to the ring network. Fig. 5, Fig. 6 and Fig. 7 shows the graph of reliability indices when DDG is connected. It has been observed that mesh network performance is better than ring network considering the reliability.

The two networks have been further modified where the DDGs have been replaced by two squirrel cage wind induction generators and reliability assessments have been done. Two $0.5 \mathrm{MW}$ diesel generators at Bus 684 and 692 of ring network and mesh networks have been replaced by two $0.5 \mathrm{MW}$ wind generation units. The reliability tests of modified networks have been conducted and the results have been summarized in TABLE IX.

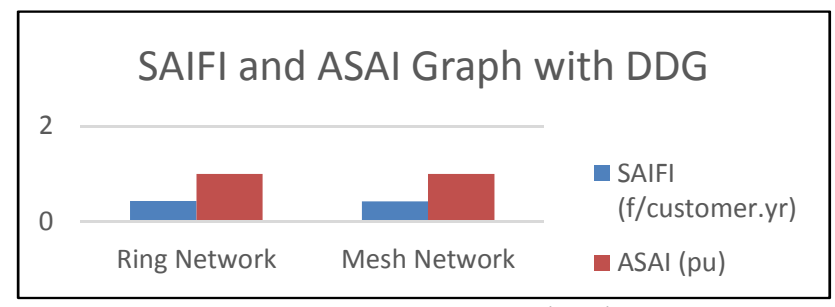

Fig. 5 SAIFI \& ASAI Graph with DDG

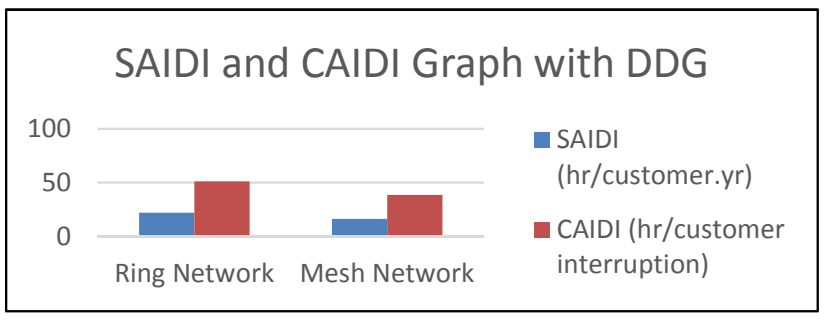

Fig. 6 SAIDI \& CAIDI Graph with DDG

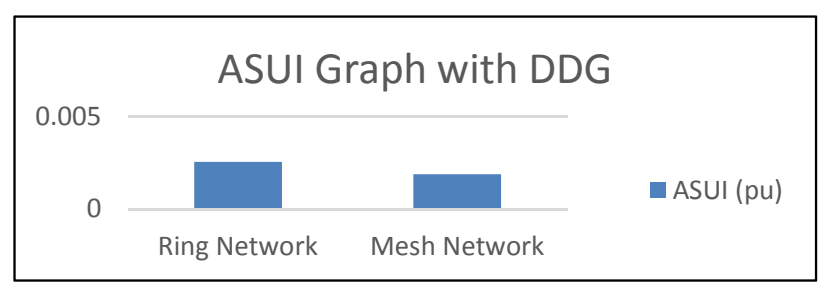

Fig. 7 ASUI Graph with DDG

TABLE IX Reliability Data of Each Network with Renewable Energy Sources

\begin{tabular}{ccc}
\hline \hline $\begin{array}{c}\text { Reliability } \\
\text { Factors }\end{array}$ & $\begin{array}{c}\text { Ring } \\
\text { Network }\end{array}$ & $\begin{array}{c}\text { Mesh } \\
\text { Network }\end{array}$ \\
\hline Average & 54.85 & 41.15 \\
Failure Rate & & \\
(f/yr) & & \\
Annual & 26.361 & 18.818 \\
Unavailability & & \\
(hr/yr) & & \\
Average & 0.4806 & 0.4573 \\
Outage & & \\
Duration (hr) & & \\
\hline \hline
\end{tabular}

It has been observed that the wind generators increase the average failure rate of each network and also increase the annual unavailability and average outage duration. The wind source itself increases the failure rate compared to diesel generators [18-21] resulting, increase in unavailability duration and outrage duration.

The modified networks with wind generators have also been tested for reliability using the reliability indices and shown in TABLE X.

TABLE X Reliability Data Based on Indices for Each Network with Renewable Energy Sources

\begin{tabular}{ccc}
\hline \hline Reliability Indices & $\begin{array}{c}\text { Ring } \\
\text { Network }\end{array}$ & $\begin{array}{c}\text { Mesh } \\
\text { Network }\end{array}$ \\
\hline $\begin{array}{c}\text { SAIFI } \\
\text { (f/customer.yr) } \\
\text { SAIDI }\end{array}$ & 0.4806 & 0.4573 \\
(hr/customer.yr) & 26.361 & 18.818 \\
CAIDI & & \\
(hr/customer & 54.846 & 41.152 \\
interruption) & & \\
ASAI (pu) & 0.9975 & 0.9982 \\
ASUI (pu) & 0.00251 & 0.00184 \\
\hline \hline
\end{tabular}


Fig. 8 shows the comparison of average failure rate of each network with and without renewable energy sources. Fig. 9 and Fig. 10 show the comparison of annual unavailability and average outage duration respectively. All this results indicates that the reliability of a system decreases with the integration of renewable energy sources.

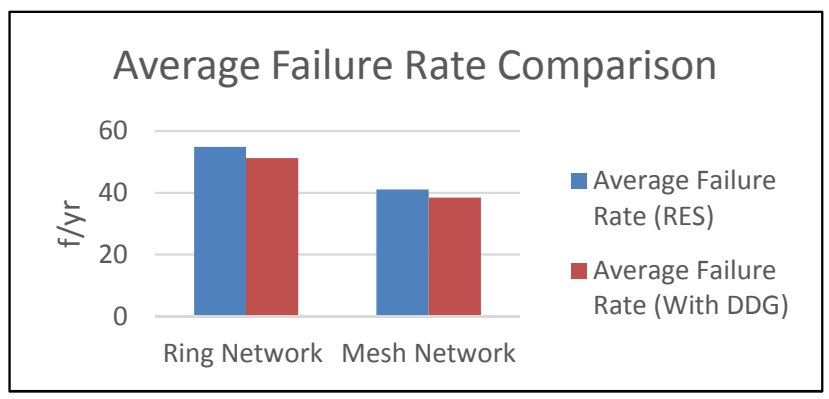

Fig. 8 Average Failure Rate Comparison Graph

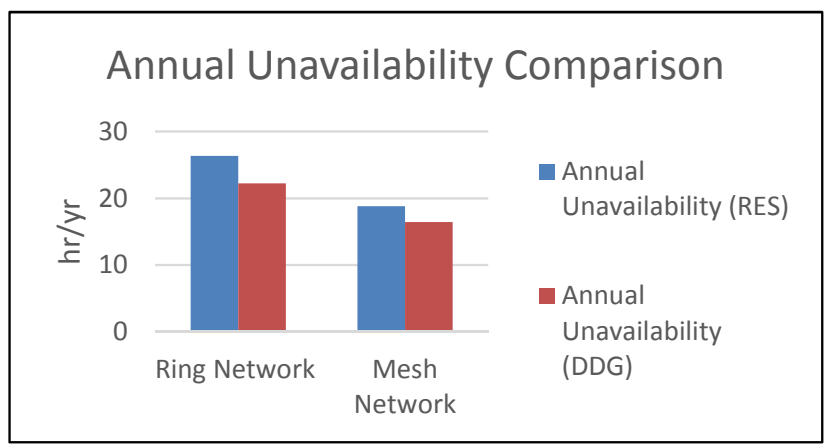

Fig. 9 Annual Unavailability Comparison Graph

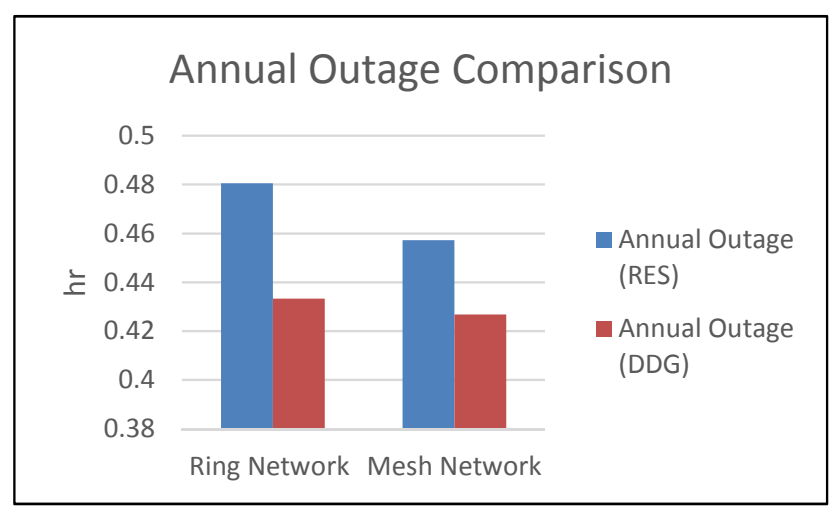

Fig. 10 Average Outage Duration Comparison Graph

\section{CONCLUSION}

This research has analyzed the reliability of ring and mesh networks based on the reliability factors and indices. The simulation results show that the reliability factors and reliability indices values are superior for the mesh network with comparison to ring network which means the mesh network has less failure rates and outage duration. The assessments for the reliability of each network with renewable energy sources have been conducted by replacing DDG units with the RES and observed that the failure rate of networks have been increased with the increase in annual unavailability and average outage duration which decreases the networks reliability. Further research will be conducted to increase the reliability of the networks with renewable energy sources in future.

\section{REFERENCES}

[1] B. Amanulla, S Chakrabarti, SN. Singh Reconfiguration of power distribution systems considering reliability and power loss. IEEE Transactions on Power Delivery, 27(2), pp: 918-26, April; 2012.

[2] K. A. Mamun,and F. R. Islam. "Reliability evaluation of power network: A case study of Fiji Islands." In Power Engineering Conference (AUPEC), 2016 Australasian Universities, pp. 1-6. IEEE, 2016.

[3] C.A. Willis, "Distribution reliability: What is it?" IEEE Industry Applications Magazine, 2(4), pp 32-37 July/August 1996.

[4] L Bertling, R. Allan, R. A. Eriksson reliability-centered asset maintenance method for assessing the impact of maintenance in power distribution systems., IEEE Transactions on Power Systems. 20(1), pp: 75-82, February 2005.

[5] L. Chang, Z. Wu,"Performance and reliability of electrical power grids under cascading failures", Electrical Power and Energy Systems, vol.33, pp: 1410-1419, 2011.

[6] A. Virendra, and R. Hakvoort. "Economic regulation of quality in electricity distribution networks." Utilities Policy 13, no. 3, pp: 211-221, 2005.

[7] R. N. Allan, Reliability evaluation of power systems. Springer Science \& Business Media, 2013.

[8] Y. Sun, H. Wang, L. Cheng and H. Liu, "Operational reliability assessment of power systems considering condition-dependent failure rate" IET Gener. Transm. Distrib. 2010, 4(1), pp: 60-72, January 2009.

[9] B. Shen, D. Koval, W. Xu, J. Salmon, S. Shen," An Analysis of Extreme-Weather-Related Transmission Line Outages", IEEE Canadian Conference on Electrical and Computer Engineering, 1998.

[10] A. Ozdemir, M. Bagriyanik, A. Kaypmaz, O. Gul, \& I. Ilisu, Impact of adverse weather conditions on outage statistics of $154 \mathrm{kV}$ Power Transmission system. In Electronics, Communications and Computers (CONIELECOMP), pp. 29-34, 2015

[11] R. Billinton and R.N. Allan, Reliability evaluation of power systems, 2nd edition, Plenum Press, New York, 1996.

[12] R. Billinton and R.N. Allan, Reliability Evaluation of Engineering Systems, $2^{\text {nd }}$ edition, Plenum Press, New York, 1992.

[13] R.E. Brown, Electrical power distribution reliability, 2002.

[14] Operation Technology, ETAP 14.1 User Guide, Dec. 2015

[15] R. Dugan, "Distribution Test Feeders - Distribution Test Feeder Working Group - IEEE PES Distribution System Analysis Subcommittee", Ewh.ieee.org, 2017. [Online]. Available: https://ewh.ieee.org/soc/pes/dsacom/testfeeders/.

[16] K. Prakash, A. Lallu, F. Islam, and K. Mamun, "Review of power system distribution network architecture," in Computer Science and Engineering (APWC on CSE), 2016 3rd Asia-Pacific World Congress on. IEEE, 2016, pp. 124-130.

[17] F. R. Islam, K. Prakash, K. A. Mamun, A. Lallu, H. R. Pota. Aromatic Network: A Novel Structure for Power Distribution System. IEEE Access. 2017 Oct 27.

[18] N.Khalesi, N. Rezaei, and M-R. Haghifam. "DG allocation with application of dynamic programming for loss reduction and reliability improvement." International Journal of Electrical Power \&Energy Systems, 33 (2),pp: 288-295, 2010.

[19] C. L. Borges, D. M. Falcao. "Optimal distributed generation allocation for reliability, losses, and voltage improvement". International Journal of Electrical Power \& Energy Systems, 28(6), pp: 413-420, 2006.

[20] R. Karki, P. Hu, R. Billinton,"A simplified wind power generation model for reliability evaluation", IEEE transactions on Energy conversion, 21(2), pp:533-540, 2006.

[21] F. Spinato, P. J. Tavner, V. Bussel, E. Koutoulakos,"Reliability of wind turbine subassemblies",IET Renewable Power Generation, 3(4), pp: 387-401, 2009. 